\title{
EDUCAÇÃO PARA A EMANCIPAÇÃO: IMPLICAÇÕES PEDAGÓGICAS NO CONTEXTO DA SOCIEDADE ATUAL
}

\author{
EDUCATION FOR EMANCIPATION: PEDAGOGICAL IMPLICATIONS IN THE CONTEXT \\ OF TODAY'S SOCIETY
}

EDUCACIÓN PARA LA EMANCIPACIÓN: IMPLICACIONES PEDAGÓGICAS EN EL CONTEXTO DE LA SOCIEDAD ACTUAL

Adriana Regina de Jesus Santos ${ }^{1}$

Marta Regina Furlan de Oliveira²

\begin{abstract}
${ }^{1}$ Doutora em Educação pela PUC/SP. Docente do Programa de Pós-Graduação em Educação da Universidade Estadual de Londrina (UEL), Londrina, PR, Brasil.
\end{abstract}

2 Doutora em Educação pela UEM. Docente do Programa de Pós-Graduação em Educação do da Universidade Estadual de Londrina (UEL), Londrina, PR, Brasil.

Resumo: Este artigo tem como objetivo refletir sobre a possibilidade de educação para a emancipação e suas implicações pedagógicas no contexto da sociedade atual. Como referenciais teóricos, partimos de algumas obras de Imannuel Kant, principalmente com o ensaio sobre Resposta à pergunta: 0 que é esclarecimento (Aufklãrung)? entre outras obras e, ainda as reflexões de Theodor Adorno e Horkheimer, principalmente, com a obra Dialética do Esclarecimento (1985), no sentido de pensar acerca do processo de educação. Kant, considerado um dos maiores filósofos alemães a partir do século XIX e mesmo do mundo, tomou para si a tarefa de pensar sobre os limites e as possibilidades do conhecimento; no sentido de que, por meio da filosofia, a humanidade pode ser compreendida e educada. Acredita o filósofo que, na e pela educação, o homem tem condições de conquistar sua maioridade e autonomia, ou seja, sua emancipação. Na mesma lógica do pensamento, Adorno nos convida ao processo de reflexão sobre a educação, no sentido de que os homens abandonem seu estado de auto inculpável menoridade em favor do projeto de emancipação humana. As contribuições desses filósofos alemães potencializam-nos a pensar e problematizar a educação, tecendo novos direcionamentos em favor da emancipação do ser humano.

Palavras-chave: Educação; Emancipação; Esclarecimento.

Abstract: This article reflects on the possibility of education for emancipation, and its pedagogical implications in the context of today's society. As theoretical references, we start with some works by Imannuel Kant, and in particular, his essay Answer to the question: What is enlightenment (Aufklärung)? among other works, and also the reflections of Theodor Adorno and Horkheimer, particularly the work Dialectic of Enlightenment (1985) in the sense of thinking about the process of education. Kant, considered one of the greatest philosophers of Nineteenth century Germany, and indeed the world, took on the task of thinking about the limits and possibilities of knowledge; in the sense that through philosophy, humanity can be understood and educated. The philosopher believes that in and through education, man is able to conquer his adulthood and autonomy, that is, his emancipation. In the same logic of thinking, Adorno invites us to the process of reflection on education, whereby men abandon their state of selfless blamelessness in favor of the project of human emancipation. The contributions of these German philosophers empower us to think about and investigate education, forging new directions in favor of the emancipation of the human being. 
Keywords: Education; Emancipation; Clarification.

Resumen: Este artículo tiene como objetivo reflexionar sobre la posibilidad de educación para la emancipación y sus implicaciones pedagógicas en el contexto de la sociedad actual. Como referenciales teóricos partimos de algunas obras de Imannuel Kant, principalmente con el ensayo sobre Respuesta a la pregunta: ¿Qué es esclarecimiento (Aufklãrung)? entre otras obras y, aún las reflexiones de Theodor Adorno y Horkheimer, principalmente, con la obra Dialéctica del Esclarecimiento (1985) en el sentido de pensar acerca del proceso de educación. Kant, considerado uno de los mayores filósofos alemanes a partir del siglo XIX e incluso del mundo, tomó para sí la tarea de pensar sobre los límites y las posibilidades del conocimiento; en el sentido de que, por medio de la filosofía, la humanidad puede ser comprendida y educada. Creer, el filósofo que en la y por la educación, el hombre tiene condiciones de conquistar su mayoridad y autonomía, o sea, su emancipación. En la misma lógica del pensamiento, Adorno nos invita al proceso de reflexión sobre la educación, en el sentido de que los hombres abandonen su estado de auto inculpable minoridad en favor del proyecto de emancipación humana. Las contribuciones de estos filósofos alemanes nos potencian a pensar y problematizar la educación, tejiendo nuevos directivos en favor de la emancipación del ser humano.

Palabras clave: Educación; Emancipación; Esclarecimiento.

\section{Apontamentos Iniciais}

Com base na ideia lançada por Kant de que o homem precisa se emancipar e superar essa menoridade para alcançar a verdadeira liberdade, temos o objetivo principal, nesse artigo, de refletir o processo de educação para a emancipação. Para esse estudo, buscamos referenciais teóricos em Kant (1992, 1996, 2003, 20015), a partir das obras A Metafísica dos Costumes (2003), Crítica da Razão Pura (2015), Crítica da Razão Prática (2015), Fundamentação da Metafísica dos Costumes (2007), Lógica (1992) e Sobre a Pedagogia (1996), do ensaio à Resposta à pergunta: O que é esclarecimento (Aufklãrung)? e, ainda, com as contribuições de Adorno e Horkheimer (1985) com a Dialética do Esclarecimento. Tendo como princípio estas obras, podemos perceber que é possível refletirmos o processo de formação humana com vista ao projeto de saída do homem de sua condição de menoridade, de seu auto inculpável menoridade em favor de um horizonte viável para a autorreflexão e a autodeterminação do homem sobre as coisas e sobre o mundo.

Para Kant (2015), ousar saber é seu maior projeto de formação humana, considerando que, à luz de um iluminismo presente, há a convicção teórica de que a menoridade do homem reside na falta de coragem de fazer uso de seu entendimento e, não necessariamente, a ausência de compreensão das coisas. Nesse sentido, procuraremos nos remeter ao campo educacional, sem desmerecer que advém de um processo formativo à luz do contexto social.

Em uma educação moral, os princípios filosóficos, procedentes do pensamento kantiano, causam questionamentos na esfera educacional. O pensador trabalha com questões que nos fazem pensar se é possível ou não a emancipação humana. E como pensar essa educação emancipada se ela é moral? E se a educação do homem pode levar a humanidade a um estágio de esclarecimento?

Há a compreensão clara de que o pensamento kantiano se constitui como um dos mais influentes nas teorias filosóficas e pedagógicas a partir do século XIX e não há dúvida alguma de que a superioridade do homem reside no saber. 
Nele estão guardadas muitas coisas, que os reis com todos os seus tesouros não podem comprar, sobre as quais não se impõe o seu mando, das quais seus informantes e alcaguetes não dão noticia alguma, cujas terras de origem não podem ser alcançadas pelos veleiros dos seus navegantes e descobridores (ADORNO, 1999, p.19).

Para tanto, Aufklärung (esclarecimento) é a resposta de Kant. Desta forma, o casamento feliz entre o saber e a liberdade se configura no processo de esclarecimento e emancipação do homem, no sentido de que o entendimento sobressaia o mito, a superstição, tendo voz de comando sobre a natureza enfeitiçada. Assim, a saída da minoridade é uma possibilidade que a humanidade desenvolveu para livrar-se do desconhecido, tendo no Iluminismo seu ponto alto como estratégia racional e crítica no processo de transformação moral do mundo. A esse processo chamamos de emancipação, ou seja, superação da minoridade do qual o próprio homem tem culpa pela sua "ignorância e preguiça de pensar por conta própria" (ADORNO e HORKHEIMER, 1985, p.07).

Desse modo, os filósofos Kant e Adorno contribuem de maneira problematizadora para o processo de compreensão da educação para a emancipação no contexto atual e uma de suas grandes contribuições consiste no movimento que aparece na Aufklärung. Como organização estrutural do texto, no primeiro momento discorremos acerca da compreensão de que temos sobre o conceito de educação e emancipação em Kant em sintonia com Adorno e Horkheimer. Em contínua discussão, enveredamos nossos olhares para o que temos de compreensão acerca do conceito esclarecimento (Aufklärung) em Adorno, a fim de que haja potenciais críticos e reflexivos para compreender o processo formativo do indivíduo e se há, por essa via, possibilidade de uma educação para a emancipação do sujeito que aprende.

\section{RefLetindo SOBRE O CONCEITO DE EDUCAÇÃO E EMANCIPAÇÃO: CONTRIBUIÇÕES PARA O PROCESSO FORMATIVO E PEDAGÓGICO}

Para compreendermos o processo educação e emancipação com seus aparatos críticos, é importante partirmos do início quando desde sempre temos clara a ideia de que o Iluminismo, no seu sentido mais abrangente, perseguiu o objetivo de "livrar os homens do medo e de fazer deles senhores". Adorno (1999) complementa ao afirmar ainda que "a terra resplandece sob o signo do infortuno triunfal" (ADORNO, 1999, p.17).

Nesse sentido, antes de compreendermos o processo de emancipação, é preciso que haja a compreensão do projeto do Iluminismo que, em sua fase inicial, era o de livrar o mundo do feitiço, dissolvendo os mitos e anulando a imaginação, pelo processo de compreensão e entendimento do saber (ADORNO, 1999).

Desse modo, Kant, considerado um dos maiores filósofos alemães e mesmo do mundo, tomou para si a tarefa de pensar sobre os limites e as possibilidades do conhecimento. De modo que, no pensamento do filósofo, destacam-se aspectos críticos e construtivos, na medida em que este considera que, por meio da filosofia, a humanidade pode ser compreendida e educada. Ou melhor, o homem é uma criatura que precisa ser educada.

Para isso, o filósofo acredita que a razão consegue propor soluções para as questões que se pretende compreender, uma vez que leva o ser humano a raciocinar sobre os elementos 
fundamentais de seu princípio e de seu fim em sua existência e, ainda, sobre os elementos constitutivos de seu pensar e agir segundo parâmetros que ele mesmo traçar e não movido por ações externas que o induz à ação sem o processo de entendimento e crítica. Para tanto, Kant estabelece o conhecimento como potencial libertador para a atuação da própria razão crítica sobre o mundo sensível. Desse modo, o homem pode encontrar a liberdade pelo conhecimento.

Podemos ver que Kant (apud ADORNO, 1999, p.17) desprezava os adeptos da tradição que "acreditam primeiro que os outros sabem o que eles próprios não sabem; e, em seguida, que eles próprios sabem o que não sabem"; uma vez que o projeto educacional de Kant era potencializar o homem para uma íntima relação entre o saber e a liberdade, que nada mais é do que o processo de emancipação humana.

Kant (apud ADORNO, 1999, p.17) acreditava que o próprio homem é culpado de permanecer nesta condição do saber e não nega que a "crueldade, a aversão à dúvida, a precipitação nas respostas, o pedantismo cultural, o receio de contradizer, a parcialidade, a negligencia na pesquisa pessoal, o fetichismo verbal, a tendência a dar-se por satisfeito com conhecimentos parciais, entre outras causas semelhantes" são os causadores desta permanência e aparente oposição do homem em relação à razão, quando se permite seduzir pelo encanto da comodidade de um saber doutrinário, superficial e domesticador. Nesse sentido, Kant é incisivo ao insistir sobre a condição de que se alguém ainda persistir em permanecer no estado de menoridade, o faz somente pela preguiça, pela covardia e pela sua própria escolha de ser guiado pelo entendimento de outro.

Nessa lógica de pensamento, podemos entender que a preguiça e a covardia são causas que permanecem em grande parte dos homens, em outras palavras, se torna cômodo ser menor, assim é mais fácil instituírem tutores. Isto porque quando os homens são instituídos de tutores, não há necessidade de esforçar-se por nada, não é necessário refletir, o mundo em si é muito perigoso, de tal maneira que é difícil para o homem livrar-se da menoridade.

Para Kant (2006), o homem do século XVIII e XIX é um homem otimista e confia no poder da luz natural - da razão -, aqui ele é contra todas as formas de obscurantismo, ou seja, de magia. Aquele que permanece nas trevas tem algo a esconder, ou seja, o valor de uma ação, de uma ideia, está em se colocar ao público. É preciso garantir e promover o esclarecimento, eles são a condição para o aperfeiçoamento moral do mundo.

A discussão kantiana é movida em defesa da crença no poder da razão, que apesar de seus limites, possibilitará a constituição de uma conduta baseada na liberdade e na crítica. 0 filósofo responde com um breve texto publicado em 1783 na revista Berlinische Monatsschrift à questão o "que é o esclarecimento?" De modo bastante objetivo, o filósofo inicia o primeiro parágrafo do seu ensaio com uma definição: "Esclarecimento Aufklärung, significa a saída do homem de sua menoridade, pela qual ele próprio é responsável, o homem precisa ter coragem de servir ao seu próprio entendimento, ou seja, ao seu esclarecimento" (KANT, 2012, p.13).

Destarte, em decorrência do medo, o homem não faz o bom uso da razão, infantilizandose diante do saber. Sua definição se associa à imaturidade, à minoridade do homem, em que se limita a incapacidade de fazer uso de seu entendimento sem a direção de outro indivíduo. Desse modo, o homem é culpado dessa minoridade e a causa disso está na falta de decisão, de coragem de servir-se de si mesmo sem a direção de outrem, o que gera um certo conformismo do saber. 
Para Kant (2012, p. 67),

Oserinfantil, o ser menor, está associado ao medo, a um estado que o homem deveria superar para tornar-se dono de si mesmo, dotado de razão e conhecimento, um estado graças ao qual "depois de terem sacudido de si mesmos o jugo da menoridade, espalharão em redor de si o espírito de uma avaliação racional do próprio valor e da vocação de cada homem em pensar por si mesmo.

Essa reflexão em Kant nos potencializa, pela razão crítica, compreender o cenário contemporâneo atual que não se distancia muito dessa lógica de covardia, de dependência e infantilização do saber. Somos conduzidos a pensar o que os outros querem que pensemos. Somos levados a tomar decisões pelos ideais e valores que outros conduzem como verdade e muitas de nossas reflexões não passam de parafraseio de outros, ou seja, criamos fórmulas, verdades, conceitos, amparados pelo que os que estão ao nosso redor e detêm o poder ditam. E, diante disso, podemos dialogar com as contribuições de Kant, em que na tentativa de libertar os homens do mito, da ignorância, criaram-se novos mitos, ou seja, "caminhando em busca da ciência moderna, os homens se despojam do sentido" (ADORNO, 1999, p.20).

Isso se explica pelo fato de que o iluminismo se auto reconhece até mesmo nos mitos. Quaisquer que sejam os mitos para os quais essa resistência possa apelar, esses mitos, pelo simples fato de se tornarem argumentos numa tal contestação, aderem ao princípio da racionalidade demolidora pela qual censuram o iluminismo (ADORNO, 1999, p.21)

O homem teria se acostumado e criado até certo amor pela sua condição de tutelado, pois é muito mais fácil absorver preceitos e fórmulas dos tutores, quanto aos comportamentos que deverão ser reproduzidos, do que o exercício da autorreflexão e da possível contestação aos mandos e aos desmandos dos senhores. Entretanto, para Kant, o "[...] uso público da sua razão deve ser sempre livre e só ele pode realizar o esclarecimento [Aufklärung] entre os homens" (KANT, 1974, p. 104).

Isto posto, para superar a condição de menoridade, Kant estimula o próprio entendimento na sua defesa efusiva: Sapere Aude! Ouse saber! O homem precisa ter a coragem de admitir que em alguns momentos de sua vida suas ações e pensamentos são controlados por outras pessoas, no entanto essa situação não é eterna, pois o indivíduo pode, por meio do uso da razão, transformar-se em sujeito.

Agora, àqueles que buscam a maioridade e conseguem fazer pelo exercício de seu próprio espírito, de pensar por si mesmo, podem almejar o esclarecimento. Por meio do uso público da razão, Kant nos aponta que o esclarecimento exige a liberdade, para ele, quando o homem é cercado de tutores e não se liberta para o raciocínio, fica limitada sua liberdade, conforme ele diz: "[...] mas ouço clamar de todas as partes: não racionai! O oficial diz: não raciocinais, mas fazei o exercício! O conselheiro de finanças: não raciocinais, mais pagai! $\mathrm{O}$ padre: não raciocinais, mas crede" (KANT, 2015, p.11).

Para Kant (2007), o uso público da razão leva a todo momento ser livre, e somente ele pode difundir o esclarecimento entre os homens. Portanto, ter esclarecimento não é apenas adquirir um profundo conhecimento sobre o assunto, e sim combinar isso com a conquista da autonomia, passo moral fundamental, apenas dado por uma minoria.

Isto posto, podemos questionar: "vivemos numa época esclarecida"? Nos dizeres de Kant: 
nela, na qual em matéria religiosa sejam capazes de fazer uso seguro e bom de seu próprio entendimento sem serem dirigidos por outrem. Somente temos claros indícios de que agora Ihe foi aberto o campo no qual podem lançar-se livremente menores os obstáculos ao esclarecimento geral ou à saída deles, homens, de sua menoridade, da qual são culpados. Considerada sob este aspecto, esta época é a época do esclarecimento (KANT, 2015. p.16).

Podemos dizer que, para Kant, é difícil desvencilharmo-nos da condição da menoridade, porque ela se fixa no indivíduo quase como uma natureza. Nesse sentido, o homem, em vez de pensar por si mesmo conceitos de que dispõe para interpretar o mundo, apenas reduz preceitos e fórmulas, utilizando-se dos conceitos pensados dos seus tutores. Agora com relação aos tutores da grande massa, o pensador alemão admite que, até entre eles não é impossível encontrar alguns homens capazes de pensamentos próprios, até mesmo homens de razão se mantêm sob a condição de um tutor.

Vivemos, em certa medida, em uma época de precário esclarecimento, vivemos em um processo de esclarecimento, um processo dinâmico em que queremos nos manter na maioridade, longe da menoridade. E, por essa razão, nos questionamos como não pensar na educação diante do exposto? Por que os homens ainda vivem na menoridade? Qual será o papel da educação?

Ainda que essa problematização faça sentido, para Kant a autonomia e a liberdade só podem se efetivar quando o homem se torna humanizado, quando ele passa pelo processo de humanização e pela aprendizagem do uso livre e autônomo da razão. O próprio pensador nos ensina, pois aquilo que afasta o homem da menoridade e, consequentemente, torna-o esclarecido, é o bom uso da razão como uma atitude.

Segundo Kant, há uma distinção entre o uso público e privado da razão. Ao responder à pergunta o que é esclarecimento, Kant afirma que é muito difícil que um homem particular esclareça a si próprio, dado que ele já se habituou a não fazer uso de seu próprio entendimento. Ao contrário, um público pode lentamente se esclarecer, pois no seu interior existem indivíduos capazes de pensamento próprio, os quais espalharão em redor de si o espírito de uma avaliação racional do próprio valor e da vocação de cada homem em pensar por si mesmo (KANT, 2015, p. 11-12). Para isso é necessário o uso público da razão, aquela que qualquer homem, como sábio, faz dela diante do grande público do mundo letrado (KANT, 2015, p. 12).

Kant não foi só um espectador das transformações e das discussões sobre a educação que ocorreram na sua época, foi um pensador que contribui intensamente com suas próprias ideias para o debate desse mesmo tema. A partir de sua obra Sobre a Pedagogia, reflete-se de que modo ele propõe a realização do processo formativo do sujeito. Em seus estudos, Kant (1996) analisa o uso da razão pública e da razão privada com o objetivo de explicar o que é o esclarecimento. Para ele, a formação cultural do homem ocorre por meio da preparação crítica do sujeito, fundada na aprendizagem do uso da razão, única forma capaz de lhe possibilitar a humanização e sua consequente culturalização.

Em sua obra Sobre a Pedagogia, admite que o homem é a única criatura que precisa ser educada. Entende por educação o cuidado de sua infância, ou seja, a disciplina e a instrução com a formação. Kant diferencia os animais dos homens, ou seja, em relação ao primeiro, não há necessidade de serem cuidados, no máximo precisam ser alimentados, aquecidos, guiados e protegidos. Já os 
homens, necessitam ser cuidados, ou seja, "[...] Por cuidados entendem-se as precauções que os pais tomam para impedir que crianças façam uso nocivo de suas forças" (KANT,1996, p.11).

Kant afirma que a disciplina transforma a animalidade em humanidade, um animal, por exemplo, é por seu próprio instinto tudo aquilo que ele pode ser; uma razão exterior a ele tomou por ele antecipadamente todos os cuidados necessários.

Quanto ao homem, ele tem necessidade de sua própria razão, nele há instintos, por si mesmo, precisa formar o projeto de sua conduta. $O$ homem precisa de cuidados especiais indispensáveis para sua sobrevivência e formação, uma vez que, para além dos cuidados requeridos para sobrevivência biológica, ele precisa aprender, dentre outras funções importante, a conviver em sociedade, a se disciplinar e a entrar no mundo cultural que define o espaço de humanidade.

Segundo o filósofo alemão, a espécie humana é obrigada a extrair de si mesma, pouco a pouco, com suas próprias forças, todas as qualidades naturais, que pertencem à humanidade, sendo que uma geração vai educando a outra. A disciplina, portanto, é o que impede ao homem de desviá-lo de seu destino, desviá-lo da humanidade. De certo modo a disciplina é puramente negativa, porque tira o homem da sua selvageria.

A instrução, ao contrário, é a parte positiva da educação. Diz "[...] A selvageria consiste na independência de qualquer lei. A disciplina submete o homem às leis da humanidade e começa a fazê-lo sentir a força das próprias lei" (KANT, 1996, p. 12-13). Neste caso, a condição para formação do homem reside na educação dada por meio de seus preceptores, por aqueles que já passaram pelo processo educacional, nas palavras de Kant (1992, pg. 53), “o homem não pode tornar-se um verdadeiro homem se não pela educação. Ele é aquilo que a educação faz dele".

De acordo com o filósofo, as crianças geralmente são mandadas cedo para escola, para que se acostumem a ficar sentadas e tranquilas, dessa forma, são capazes de obedecer, a fim de que no futuro elas não sigam de fato apenas os seus caprichos. O homem é tão naturalmente inclinado à liberdade que, depois que se acostuma a ela, tudo sacrifica. Ora, por essa razão é conveniente recorrer cedo à disciplina. O homem tem necessidade de cuidados de formação. Portanto, a formação compreende a disciplina e a instrução.

Para Kant, a falta de disciplina e de instrução em certos homens os torna mestres muito ruins de seus educandos. Afirma na obra Sobre a Pedagogia "[...] A falta de disciplina é um mal pior que a falta de cultura, pois esta pode ser remediada mais tarde, ao passo que não se pode abolir o estado selvagem e corrigir um defeito de disciplina" (KANT, 1996. p.17).

Aí reside, para Kant, a importância em relação à educação, pois por meio dela as gerações futuras podem dar um passo a mais em direção ao aperfeiçoamento da humanidade, uma vez que o segredo da perfeição da natureza humana se esconde no próprio problema da educação.

Para compreender melhor essa ideia, Kant ressalta que o projeto de uma teoria da educação é um ideal nobre, mesmo que ele não possa ser realizado, o que não nos impede de considerá-lo como uma ideia para se concretizar no futuro. O próprio autor nos chama atenção para esse argumento, diz que uma ideia não é outra coisa senão o conceito de uma perfeição que ainda não se encontra na experiência. 
Assim, segundo o conceito kantiano, a educação é uma arte, cuja prática necessita ser aperfeiçoada por várias gerações. Portanto, cada geração, de posse dos conhecimentos das gerações precedentes, possui melhores condições para educar gerações posteriores.

Sendo assim, compete ao homem extrair de si o bem, a ele compete desenvolver a felicidade e a infelicidade, Kant diz: "[...] Tornar-se melhor, educar-se e, se se é mau, produzir em si moralidade: eis o dever do homem" (KANT, 1996, p.21). A educação, portanto, é o maior e o mais árduo problema que pode ser proposto aos homens, conhecimento e educação dependem um do outro. Por essa razão, a educação não pode ser lançada à frente sem que as experiências e o conhecimento das gerações antecedentes transmitam algo para gerações seguintes.

Diante disso, podemos questionar se a educação dos indivíduos deve imitar a cultura das gerações anteriores? Porque nos parece que a partir desta questão nos deparamos com outro problema, o da arte de governar os homens e a arte de educá-los.

Nesse sentido, Kant nos ensina que, uma vez que as disposições naturais do ser humano não se desenvolvem por si mesmo, toda educação será uma arte, assim como o progresso pode ser mecânico ou raciocinado. No entanto, na arte mecânica, haveria erros e lacunas, pelo fato de não obedecer a nenhum plano.

A arte da educação ou Pedagogia, como ele diz, "[...] deve, portanto, ser raciocinada, se ela desenvolver a natureza humana de tal modo que esta possa conseguir o seu destino" (KANT, 1996, p.23). Nota-se ainda que a preocupação Kantiana é educar os homens segundo o presente estado da espécie humana, mas segundo um estado melhor, possível no futuro, segundo a ideia de humanidade e da sua inteira destinação. Pensar uma boa educação é justamente a fonte de todo bem e para isso é necessário que o homem a ser educado seja disciplinado, no sentido de domar a selvageria.

Desse modo, em termos kantianos, o homem deve tornar-se culto, a cultura é a forma de abranger a instrução e os vários conhecimentos. Kant afirma ainda que a cultura é a criação da habilidade, e esta é a posse de uma capacidade condizente com todos os fins que almejamos. A educação deve-se dar para que o homem se torne prudente e moralizado, convém ensinar ao homem escolher apenas os bons fins. Bons nesse sentido são aqueles fins que são aprovados por todos e que podem ser, ao mesmo tempo, os fins de cada um.

Enfim, é preciso educar os homens para que aprendam a pensar. A educação deve apoiar-se em princípios (morais), portanto a educação abrange cuidados na formação do indivíduo. Para Kant, a educação pode ser negada quando impede os defeitos; e positiva, quando se tem um direcionamento, ou seja, conduz na prática daquilo que foi ensinado.

Para entender melhor essa ideia, revisitamos um dos maiores desafios da educação segundo Kant, que é conciliar a submissão ao constrangimento das leis com o exercício da liberdade. Kant nos diz que é preciso habituar o educando a suportar que sua liberdade seja submetida ao constrangimento de outrem, e que, ao mesmo tempo, dirija corretamente sua liberdade.

Para isso, é necessário que o educando sinta a inevitável resistência da sociedade, para com isso apreender a conhecer o quanto é difícil bastar-se a si mesmo e tolerar as privações e adquirir o que é necessário para tornar-se independente. Segundo Kant: 
$1^{\text {a }}$ - É preciso dar liberdade à criança desde a primeira infância e em todos os seus movimentos (salvo quando pode fazer mal a si mesma, como, por exemplo, se pega uma faca afiada), com a condição de não impedir a liberdade dos outros, como no caso de gritar, ou manifestar a sua alegria alto demais, incomodando os outros. $2^{\mathrm{a}}$ - Deve-se-Ihe mostrar que ela pode conseguir seus propósitos com a condição de que permita aos demais conseguir os próprios; por exemplo, nada se fará que lhe seja agradável, se não fizer o que desejamos, ou seja, aprender o que lhe é ensinado, e assim por diante. $3^{\mathrm{a}}$ - É preciso provar que o constrangimento, que Ihe é imposto tem por finalidade ensinar e a usar bem da sua liberdade, que a educamos para que possa ser livre um dia, isto é, dispensar os cuidados de outrem. (KANT, 1996. p.35).

De um modo geral, a liberdade é fazer um uso público da sua razão, para que todo ser humano em sua vida privada desempenhe funções, fazendo algum trabalho que obedeça às regras para determinados ofícios que lhe são designados. Assim, esse mesmo indivíduo pode e deve dirigir-se à comunidade e manifestar seu pensamento sobre os assuntos de interesses gerais. Ao mesmo tempo ele pode ser um educador, um cobrador de impostos, um representante da igreja; são homens que desempenham seu uso privado da razão, mas que também fazem o uso público de sua razão manifestando-se sobre interesses da comunidade.

Por meio destas colocações do pensador, entende-se que a emancipação não consiste em uma categoria estática, "mas como uma categoria dinâmica, como um vir a ser e não um ser." Entretanto, não desconsidera a relevância das normas sociais e as condições necessárias para a saída do estado de menoridade (ADORNO, 2003, p. 181).

Assim, Adorno traz a ideia de que para Kant,

a possibilidade de emancipação depende do contato com um modelo de autoridade: Mas de maneira alguma isto deve possibilitar o mau uso de glorificar e conservar essa etapa, e quando isso ocorre os resultados não serão apenas mutilações psicológicas, mas justamente aqueles fenômenos do estado de menoridade no sentido da idiotia sintética que hoje constatamos em todos os cantos e paragens. (ADORNO, 2003, p. 177).

Na moralidade, pressupõe-se um sujeito racional que é determinado às leis da natureza. Tudo na natureza age segundo leis. Só um ser racional tem a capacidade de agir segundo a representação das leis, isto é, segundo princípios, ou: só ele tem uma vontade (KANT, 1996). Como para derivar as ações das leis é necessária a razão, a vontade não é outra coisa senão razão prática.

[...] Se a razão só por si não determina suficientemente a vontade, se esta está ainda sujeita a condições subjectivas (a certos móbiles) que não coincidem sempre com as objetivas; numa palavra, se a vontade não é em si plenamente conforme à razão (como acontece realmente entre os homens), então as ações, que objetivamente são reconhecidas como necessárias, são subjectivamente contingentes, e a determinação de uma tal vontade, conforme a leis objectivas, é obrigação (Nötigung); quer dizer, a relação das leis objectivas para uma vontade não absolutamente boa representa-se como a determinação da vontade de um ser racional por princípios da razão, sim, princípios esses porém a que esta vontade, pela sua natureza, não obedece necessariamente. (KANT, 2007, p. 19).

De um modo geral, a partir destas reflexões, compreendemos que cabe à educação buscar, sobretudo pela disciplina, maneira para formar o sujeito capaz de compreender as regras e a capacidade de acolher suas próprias leis, ou seja, uma educação que consiste na capacidade de pensar por si mesmo, desenvolvendo assim a moral. $\mathrm{O}$ discurso de que a educação moral propicia ao ser humano autodeterminação pode parecer um tanto paradoxal. No entanto, Kant apresenta a moralidade como aquilo que só é possível com a aquisição da racionalidade, pela universalidade do pensar e do agir. 
Para o filósofo,

Um dos maiores problemas da educação é o de poder conciliar a submissão ao constrangimento das leis com o exercício da liberdade. Na verdade, o constrangimento é necessário! Mas, de que modo cultivar a liberdade? É preciso habituar o educando a suportar que a sua liberdade seja submetida ao constrangimento de outrem e que, ao mesmo tempo, dirija corretamente a sua liberdade. Sem esta condição, não haverá nele senão algo mecânico; e o homem, terminada a sua educação, não saberá usar sua liberdade. É necessário que ele sinta logo a inevitável resistência da sociedade, para que aprenda a conhecer o quanto é difícil bastar-se a si mesmo, tolerar as privações e adquirir o que é necessário para tornar-se independente. (KANT, 1996, p. 34).

Assim, a autonomia da vontade possibilita o indivíduo se tornar humano, abandonando seu estado de anomalia, o ser humano não é um ser moral por natureza, o homem torna-se moral somente quando eleva sua razão até aos conceitos de dever e da lei. Kant descreve:

Pode-se, entretanto, dizer que o homem traz em si tendências originárias para todos os vícios, pois tem inclinações e instintos que o impulsionam para um lado enquanto que sua razão o impulsiona ao contrário. Ele, portanto, poderá tornar-se moralmente bom apenas graças à virtude, ou seja, graças a uma força exercida sobre si mesmo, ainda que possa ser inocente na ausência dos estímulos (KANT, 2006, p.95).

De algum modo, a moralização não pode ser considerada apenas como parte da cultura e da civilização. Ao que parece, ela envolve uma passagem para o estado da liberdade, pressupondo os passos preparatórios da cultura e da civilização. O que, para Kant, a humanidade não se configura no estágio de moralização, ainda estamos em treinamento disciplinar, o estágio para uma moralização, aconteceria por meio da educação, moralizando os indivíduos. Um processo pelo qual sai do estado de natureza selvagem do ser humano para entrar em um estado esclarecido, em que a razão se sobressaia.

Na concepção kantiana, a educação propõe a formação de um ser humano ideal, de forma que a autonomia desse indivíduo se dará, no bom uso da razão, dependendo da sua saída da menoridade para o esclarecimento, ou seja, ser livre, possuir autonomia. É desse modo que Kant discute nos seus escritos, dizendo que o homem deve pensar por si mesmo, julgando questões segundo seu próprio conceito, seguindo sua autonomia intelectual.

O papel da reflexão ou da razão autônoma não está em treinar a memória e nem a erudição, mas possibilitar a formação do indivíduo esclarecido. O processo educacional, assim como evidencia Kant, tem, por um lado, educar para si quando a educação assume a característica de formar o homem indivíduo. E, por outro lado, educar-se para o outro, quando a educação pensa a cidadania.

Em termos gerais, os seres humanos são os únicos responsáveis pela sua formação e conduta de si. Ele é capaz de criar e reviver sua própria história, sendo capaz de fazer suas próprias escolhas, ou seja, o homem é homem pela sua condição de ser livre, sendo a liberdade uma condição da existência humana, o homem é livre para escolher, já que possui consciência.

Ao passo que essa consciência gera a intencionalidade das ações praticadas na sociedade, traz, portanto, a responsabilidade com seu destino e com o dos outros à sua volta. O homem, ao escolher, representa sua própria humanidade, tornando-o responsável por aquilo que escolher ser.

Não vemos como um problema quando dizemos que, ao instruir os seres humanos, vamos 
torná-los servos, ao contrário disto, não quer dizer torná-los iguais, mas sim viabilizar um diálogo comum, permitindo que ele se reconheça no coletivo, assim, esclarecer um povo é o mesmo que educá-lo. O próprio Kant ressalta que apenas por meio da educação é possível ao indivíduo almejar a liberdade, é pela educação que é possível se estabelecer uma sociedade esclarecida.

Portanto, o indivíduo precisa aprender sua liberdade por meio dos seus atos. Assim sendo, a liberdade do indivíduo está perpetuamente em meu ser; não se trata de uma qualidade sobreposta ou uma propriedade da natureza; precisamente a textura está na existência do ser (SARTRE, 1998, p.542-543).

\section{Aproximações Finais}

A pesquisa teórica objetivou as posições filosóficas de Kant e Adorno e Horkheimer relacionadas à possibilidade de uma educação esclarecida, emancipada. O Iluminismo se apresenta como o movimento histórico de possível saída da condição desta minoridade à luz de novos caminhos com o uso da própria razão. Desse modo, essa discussão continua sendo recorrente na contemporaneidade e permeia o projeto educacional e pedagógico para a emancipação, a racionalidade, a liberdade do saber.

Nesse sentido, a educação, no sentido emancipatório, tem o importante papel de perceber a barbárie e revelar as suas raízes, examinando as condições para interferir em seu rumo. A emancipação na concepção de Kant não é somente o desenvolvimento intelectual do pensamento, a superação da ignorância no processo histórico, mas é também a capacidade dos homens de se libertar da dominação e da opressão geradas por eles próprios.

À luz dos pressupostos kantianos, podemos tecer aproximações em Adorno (2003) quando, ao se referir ao processo de educação, traz como caminho possível para que o sujeito, em processo emancipatório, tenha a coragem e a decisão para usar o próprio entendimento do mundo e com o mundo. De certo modo, esse processo de educação para a emancipação está relacionado ao processo de tomada de consciência e a própria racionalidade para a autocrítica e autorreflexão.

A educação seria impotente e ideológica se ignorasse o objetivo de adaptação e não preparasse os homens para se orientarem no mundo. Porém, ela seria igualmente questionável se ficasse nisso, produzindo nada além de well adjusted people, pessoas bem ajustadas, em consequência do que a situação existente se impõe precisamente no que tem de pior. (ADORNO, 2003, p. 143).

Desse modo, a educação coloca-se diante de determinada situação, permeando por diversas possibilidades, que seja uma produção de uma consciência verdadeira. Em regras gerais, a educação é entendida como aquela que torna consciente o inconsciente, pois o indivíduo pode ter ciência de seus próprios mecanismos, suas limitações e potencialidades. Para tanto, seria possível o indivíduo, como sujeito autônomo e emancipado, identificar o motivo pelo qual agiu de determinada maneira ou outra.

Nesse sentido, a educação tem a possibilidade de refletir justamente acerca de uma nova possibilidade, relacionando a racionalidade e a dominação, e não somente pela subordinação. É de nosso interesse não colocar à educação como papel salvador, mas aquela que possibilita 
pensar o mundo, lidar com a multiplicidade de signos e imagens nos quais os indivíduos estão diariamente mergulhados. A principal referência deste processo é o educador ou aqueles que se colocam como tutores esclarecidos, como os governantes e os mestres que fazem uso da autoridade e tentam legitimá-la por meio do saber e do poder, impedindo, assim, o homem fazer uso de seu próprio entendimento e de tornar-se autônomo.

No contexto dessa problematização, Kant conclui que o Esclarecimento (Aufklärung) significa a saída do homem de sua menoridade, identificando que o próprio homem é responsável e precisa ter coragem de servir ao seu próprio entendimento. Portanto, segundo o filósofo alemão, a espécie humana é obrigada a extrair de si mesma as qualidades naturais.

\section{REFERÊNCIAS}

ADORNO, T. Educação e emancipação. Trad. Wolfgang Leo Maar. São Paulo: Paz e Terra, 2003.

ADORNO, T. Os pensadores: Textos Escolhidos. São Paulo: Editora Nova Cultura, 1999.

HORKHEIMER, M.; ADORNO, T. Dialética do esclarecimento. Trad. Guido Antonio de Almeida. Rio de Janeiro: Jorge Zahar, 1985.

KANT, I. A Metafísica dos Costumes. Trad. Edson Bini. Bauru (SP): Edipro, 2003.

KANT, I. Antropologia de um ponto de vista pragmático. Tradução: Clélia Aparecida Martins. São Paulo: Iluminárias, 2006.

KANT, I. Crítica da Faculdade do Juízo. Tradução: Valerio Rohden e Antônio Marques. 3. ed. Rio de Janeiro: Forense Universitária, 2012.

KANT, I. Crítica da Razão Pura. Tradução: Fernando Costa Mattos. 4. ed. Petrópolis, Rio de Janeiro: Vozes; Bragança Paulista, São Paulo: Editora Universitárian São Francisco, 2015.

KANT, I. Crítica da Razão Prática. Tradução: Valerio Rohden. 2. ed. São Paulo: Martins Fontes - Selo Martins, 2015.

KANT, I. Crítica da Razão Prática. Tradução: Antonio Carlos Braga. 3. ed. São Paulo: Editora Escala, 2016.

KANT, I. Fundamentação da Metafísica dos Costumes. Tradução: Paulon Quintela. Lisboa: Edições 70, Ltda., 2007.

KANT, I. Lógica. Tradução: Gottlob Benjamiäsche de Guido Antônio de Almeida. Rio de Janeiro: Tempo Brasileiro, 1992.

KANT, I. Sobre a Pedagogia. Tradução: Francisco C. Fontanella. São Paulo: Editora UNIMEP, 1996.

KANT, I. Resposta à pergunta: que é esclarecimento (Aufklãrung)?. In: KANT, I. Textos seletos. Petrópolis: Vozes, 1974. p.101 -117.

KANT, I. Sobre a pedagogia. trad. de Francisco Cock Fontanella. Piracicaba: Ed. UNIMEP, 1996.

SARTRE, J. P. O ser e o nada-ensaio de ontologia fenomenológica. Tradução: Paulo Perdigão. 6 ed. Rio de Janeiro: Vozes, 1998, p.782. 
DoI: $10.14210 /$ contrapontos.v18n3.p164-176

Artigo recebido em: 19/04/2018

Aprovado em: 12/07/2018

Contato para correspondência:

Adriana Regina de Jesus Santos.

E-mail: adrianatecnologia@yahoo.com.br 